\title{
An Active Learning Framework for Ecological Intelligence: Using Activities of Multiple Intelligences to Achieve Ecological Awareness
}

\author{
Nalan Akkuzu Güven*, Melis Arzu Uyulgan \\ Department of Mathematics and Science Education, Faculty of Education, Dokuz Eylul University, Buca, Izmir, Turkey \\ *Corresponding Author: nalan.akkuzu@gmail.com
}

\section{ABSTRACT}

The current paper aimed to identify the relation between ecological intelligence (EI) and the types of multiple intelligences (MI); and pointed out how ecological awareness could be raised through activities of MI. Data were gathered from the freshman students $(\mathrm{n}=68)$ who studied at the Department of Primary Education. Four measures were used in this case study: interviews, multiple intelligence inventory, ecological intelligence scale (EIS), and students' 5-min notes. Correlation analysis was used to find the relationship between the students' ecological intelligence and the types of MI. The responses to interview questions were coded into discrete themes. Findings indicated that the intelligence type which had the most correlation with the sub-dimensions of EIS was InterP. Moreover, moderate relations were determined between the sub-dimensions of EIS and the types of MI which were Bodily/Kinesthetic (BK) and Visual/ Spatial (VS). Although the students had difficulties in activities such as drama and role-playing for BK intelligence, they enjoyed, and had better motivation to learn collaboratively during the activities through visual tools. Ecological intelligence relates to various types of MI. Based on this assertion the activities of MI should be integrated in-class environmental activities for students to acquire ecological awareness and sensitivity.

KEY WORDS: Ecological awareness, Environmental education, Environmental issues, Theory of multiple intelligences

\section{INTRODUCTION}

I $\mathrm{t}$ is a commonly held opinion that Earth is gasping due to human activities. Many studies have confirmed the environmental damage caused by human activities (Goleman et al., 2010; Koger, 2013; Steffen et al., 2007; Steffen, 2013). To protect the Earth from further various environmental issues such as global warming, climate change, and ozone layer depletion, we must take essential steps to protect the environment. First of all, it is very crucial to develop the "ability to adapt to our ecological niche" (Goleman, 2009. p. 93). The development of this ability is only possible by discovering a new kind of consciousness in the minds of every individual. Because although the human mind works well in perceiving and responding to certain hazards in the field of view of nature, it is unfortunately weak in the increasing environmental threats faced today (Goleman, 2009; McCallum, 2008). This situation falls outside the limits of human perception threshold and prevents making visible the uncertain in the future. Goleman (2009) states that although the human brain is extremely alert to the threats it feels; it is not prepared for what it encounters on the ecological front and that these threats fall beyond the threshold of our sensory perception. On the ecological front, these threats can be microscopic or global, and it has been argued are leading to higher rates of cancer and a warming planet (Beck, 2009;
Leka et al., 2010). Therefore, to survive, human beings must be able to perceive risks beyond the threshold of perception and change the system of responding to ecological hazards. To do so, it is needed to further improve ecological awareness of individuals and to make sure that they achieve a different form of ecological perspective or perception (Sterling, 2009; Wang et al., 2010). This form of perspective also requires multidisciplinary knowledge and evolves going hand in hand with various types of intelligences such as social, emotional, and intrapersonal intelligence (Goleman et al., 2012). Considering the studies reporting that different types of intelligences are associated with the attainment of ecological awareness, the system of thoughts here encompasses social, psychological, and cognitive dimensions that act in harmony all together (Basu and Mermillod, 2011; Jeronen et al., 2009; Vaughan et al., 2003). The present study, therefore, intended to investigate the relation between ecological intelligence, a new form of conscience, and types of multiple intelligences (MI), while also providing an insight into how to raise ecological awareness through activities of MI.

\section{LITERATURE REVIEW}

\section{The Concept of Ecological Intelligence}

Ecological intelligence is a new kind of conscience that addresses the globally-encountered environmental issues 
with a different ecological approach. Ecological refers to understanding of organisms and their ecosystem (Thakur, 2008; as noted in Maria, 2020) while intelligence refers to learning through experiencing and managing our environment efficiently (Goleman, 2009). Intelligence evolves in an individual's life as a result of dynamic interaction between biology, psychology, and cultural context. Intelligence therefore has a complex and multiple structure and is open for improvement through education. Acquiring ecological knowledge is also possible through interaction with others and within a community. To give an example, environmental activities where students collaborate and what experiences they acquire during such activities can help them have a better understanding of how the nature and the actions of humans are connected and how the natural world works (Goleman et al., 2010). However, to achieve ecological intelligence, these interactions need to be adaptable, so they ensure the continuity of the proper connection between an individual and the nature (Yinger and Hendricks-Lee 1993).

Ecological intelligence is sensuous, cognitive, and sympathetic consciousness that all living things are interconnected and have intrinsic value in their own right (Hornbuckle, 2008; Shumba, 2011; Sterling, 2009). Goleman (2009) stated that ecological intelligence relies on not only the knowledge or cognitive components of environmental issues but also the perceptions and sensitivity of their impact. People who have ecological intelligence know about how things and nature work and they have capacity to perceive interconnections between people's actions and their hidden impacts on planet, human health, and social systems. Based on these definitions, Goleman (2009) maintains that individuals with ecological intelligence act consciously knowing what impacts they have on the ecosystem, support improvements, as well as share what they have learnt with others and become an environment-friendly producer and consumer. In a study where Akkuzu (2016) bases the theory therein on Goleman's (2009) definition of ecological intelligence, Akkuzu highlights four different dimensions of the ecological intelligence. Addressing the ecological problems caused especially by consumption behaviors in economical, social, and environmental terms, these sub-dimensions are ecologically conscious purchasing behavior (ECPB), hidden ecological impacts of products (HEIP), ecological sensitivity (ES), and ecological knowledge sharing (EKS). Exhibiting these behaviors and characteristics required by ecological intelligence is only attained through mindful awareness.

\section{The Role of Ecological Intelligence in Environmental Education (EE) Based on Theory of Multiple Intelligence (TMI)}

Given the fact that humans are not naturally-born environmentalists and have a poor perception and consciousness of the nature, it should be clear that ecologically-intelligent abilities are to be acquired through learning. Marinescu and Burcea (2012) state that lack of education in general terms and specifically lack of ecological education resulted in attitudes that cause individuals to adopt destructive behaviors.
To prevent it, one of the most important responsibilities of schools is to make sure that individuals obtain ecological consciousness and sensitivity (Kainth, 2009). EE is therefore critically essential to raise students who will take on active roles in protecting the nature by making conscious decisions and acting in an environment-friendly way (Goleman et al., 2012). To enable students to propose long-lasting solutions for ecological problems through EE, it is necessary that ecological consciousness, knowledge, values, manners, and experiences are all attained simultaneously (Eilam and Trop, 2012; Sethusha, 2006; Vaughan et al., 2003). Numerous studies further emphasize that, to be able to achieve them, students need to participate in various activities where they are actively engaged (Staples et al., 2019) and practice and improve their competencies (Wiek et al., 2011), and the different types of intelligences they have (Al-Balhan, 2006; Baş, 2010; Goleman et al., 2010; Petruta, 2013). Therefore, a pioneering teaching strategy that draws attention to individual differences, the teaching strategy that is based on Gardner's theory of MIs is commonly encountered in practices of EE.

The TMI is mainly based on Piaget's idea that maintains children develop individually and have varying styles of learning in education. Children learn and comprehend knowledge in varying ways as they grow up (Piaget, 1969), which affects the decisions concerning the teaching methods that seek a balance between creative/intuitive and scientific/ rational dimensions of educations (Gruenewald, 2003; Zoldosova and Prokop, 2006). Inspired by Piaget's ideas, Gardner (1983) addressed the TMI for the $1^{\text {st }}$ time in his book Frames of Mind: The TMIs and emphasized that intelligence was multiple and could be exhibited in varying manners in education. The theory is essentially based on teaching practices that allow students to make use of and improve all their competencies, interests, and desires. Based on the idea that MI mostly work together in harmony instead of running separately, this theory also hints at how ecological intelligence develops. For example, Goleman et al. (2012) maintain that social and emotional intelligence extend students' competencies of seeing from another's perspective, empathizing, and showing concern while ecological intelligence applies these capacities to an understanding of natural systems and melds cognitive skills with empathy for all of life. Contrary to the modern education that intends to raise rational individuals, EE focuses on achieving an understanding of human dependence on holistic socioecological systems that encompass limits of humankind's life, questions of will and desire, social responsibility, emotions, imagination, and embodied knowing (Kagawa and Selby, 2010; Sterling, 2009; Wolff, 2011). This requires MI and ways of knowing, reframing of the skills, making synthesis, and coping with uncertainty (Sterling, 2009).

It is therefore argued that types of intelligences should be considered indissociable in EE and that different fields of intelligence are associated with each other and contribute to ecological consciousness all together. McCallum (2008) notes that varying forms of consciousness also collaborate with 
ecological intelligence in raising environmental awareness of students. Similarly, Jeronen et al. (2009) underline that EE based on MI enhance environmental awareness, environmental sensitivity, understanding of environmental problems, taking on responsibilities, and knowledge of the nature and the ecology while also further improving environmentallyconscious emotions and values and the competencies and qualifications of importance for protection of the nature. Based on all this, we can state that the ecological abilities needed to survive life's challenges involve a collaborative intelligence discovered and accomplished as a species. Furthermore, we are aiming in our research at emphasizing ecological intelligence stimulated within the lessons taught by the students carrying out the MI activities. In carrying out the research we focused on the following objectives:

- Identifying the relation between ecological intelligence and the types of MI

- Pointing out how ecological awareness can be raised through activities of MI.

\section{METHODOLOGY}

We used case study method to examine closely the data within our research context. Case studies provide specific answers to a given problem that will be applicable in addressing the context under investigation (Yin, 2017). The researchers explore a single entity or phenomenon (the case), bounded by time and activity (an event, process, institution, or social group), and collect detailed information using a variety of data collecting procedures during a sustained period of time (Gerring, 2017).

\section{Participants}

The participants consisted of $1^{\text {st }}$ year students $(n=68)$ who studied at the Department of Primary Education, Division of Elementary Teaching. The research was implemented from March to May 2019 in the EE course. The application was carried out with the participation of the researchers in different lecture hours in two classes. Demographic information was gathered from each participant (for example, age, gender, course class). $65 \%$ of the students were female, $35 \%$ of them were male and ages ranged from 18 to 22 . After the research aims were explained to the participants, all students were asked to participate in the research and their informed consents were obtained. The personal information of the participants was kept confidential and the data was only used for research purposes. Participants had the right to freely choose whether or not to contribute to the research (British Educational Research Association, 2011 as cited in Taber, 2014).

\section{Instruments}

As a form of data triangulation, we used multiple ways of obtaining qualitative and quantitative data. We collected data by interviews, MI inventory, ecological intelligence scale (EIS), and students' notes.

Multiple Intelligence Inventory (MII)

MII was proposed by Gardner (1983). In this study, "MII" translated into Turkish by Saban (2002) was used. The inventory consisted of 8 sections and 10 items in each section, a total of 80 items. Items were prepared according to the five-point grading system. These were classified as: Not suitable for me (0), slightly suitable for me (1), partially suitable for me (2), fairly suitable for me (3), completely suitable for me (4) (Saban, 2002). The scores that each student received from the inventory were added up and the total scores for intelligence types were revealed. While the reliability coefficients for each of the sub-sections of the scale ranged from 0.72 to 0.89 , it was calculated as 0.84 for the entire scale. For each intelligence type, the minimum score was 10 and the maximum score was 50 . The total scores in the types of intelligences were determined as those between 33 and 40 were "very highly developed," 25-32 were "highly developed," 17-24 were "moderately developed," 9-16 were "slightly developed," and 0-8 were not developed (Saban, 2002).

\section{EIS}

To measure the ecological intelligence levels of the students we utilized the "Ecological Intelligence Scale" (EIS) developed by Akkuzu (2016). The EIS is a 5-point Likert type scale (Always [5]; Often [4]; Sometimes [3]; Rarely [2]; and Never [1]). It consists of 41 items and has four sub-dimensions named as ECPB, EKS, ES, and HEIP. The minimum score was 41 and the maximum score was 205 . Statistical reliability was measured by the Cronbach's alpha $(\alpha)$ value for each dimension ranged from 0.70 to 0.86 . Refer to Table 1 for detailed information about the EIS.

\section{5-min Notes Following the Group Activities}

Students took notes for $5 \mathrm{~min}$ about the ecological intelligence dimension evoked by the types of MI after they watched each group's presentation. They responded to all sub-dimensions by circling one of four response options accompanied by visual cues. We analyzed the highest frequency of the dimensions in the students' notes and matched them with the related types of MI.

\section{Interviews}

Structured interviews were conducted with students face-to-face by two researchers at the end of the procedure. The students were asked four questions based on the aim of the study to explore the relation between their ecological intelligence and activities based on TMI. Participants gave their informed consents to be interviewed and audio-recorded. Interviews lasted for approximately 15-20 min and were transcribed verbatim.

\begin{tabular}{|c|c|c|c|}
\hline Sub-dimensions & Definitions of sub-dimensions & $\alpha$ & NI \\
\hline ECPB & $\begin{array}{l}\text { Assesses what individuals pay attention to } \\
\text { when purchasing products }\end{array}$ & 0.86 & 14 \\
\hline HEIP & $\begin{array}{l}\text { Considers the hidden impacts that } \\
\text { individuals create in the ecosystem during } \\
\text { the production and consumption stages of } \\
\text { the products they purchase }\end{array}$ & 0.82 & 12 \\
\hline ES & $\begin{array}{l}\text { Reveals individuals' awareness and } \\
\text { sensitivity to ecological problems }\end{array}$ & 0.80 & 10 \\
\hline EKS & $\begin{array}{l}\text { Emphasizes the importance of sharing } \\
\text { information about ecology }\end{array}$ & 0.70 & 5 \\
\hline
\end{tabular}




\section{Study Procedure and Data Collection}

We used an active learning environment in EE to implement the teaching and learning process. To offer students a variety of learning activities, we planned the context in five parts. Students were assigned to be in one of five groups. Each group consisted of between 6 and 7 students. Each group had a part of the course context (for example, Group 1: Water pollution, Group 2: Air pollution), Figure 1. A total of 68 participants took part in the study conducted in two classes (1A and 1B) which were both part of the intervention. Before the process, we informed students about ecological intelligence and about TMI. The procedure continued for 9 weeks. Refer to Figure 1 to view the procedure for this study. Students worked to create activities related to types of MI for their group context. Each group conducted one 90-min lesson to present their activities. The students were involved in various activities, such as: drama, games, songs, interactive competitions, and interviews. Figure $2 \mathrm{a}-\mathrm{d}$ to view some pictures of the group

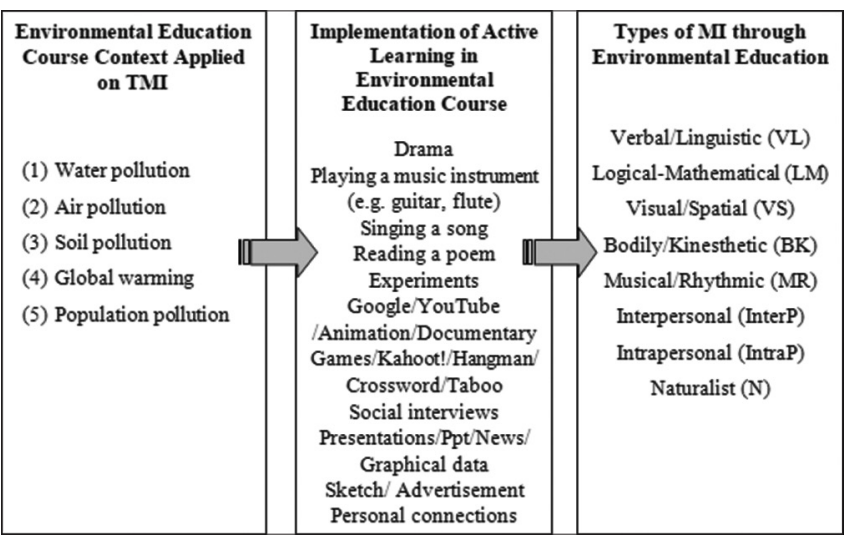

Figure 1: The context of the study procedure
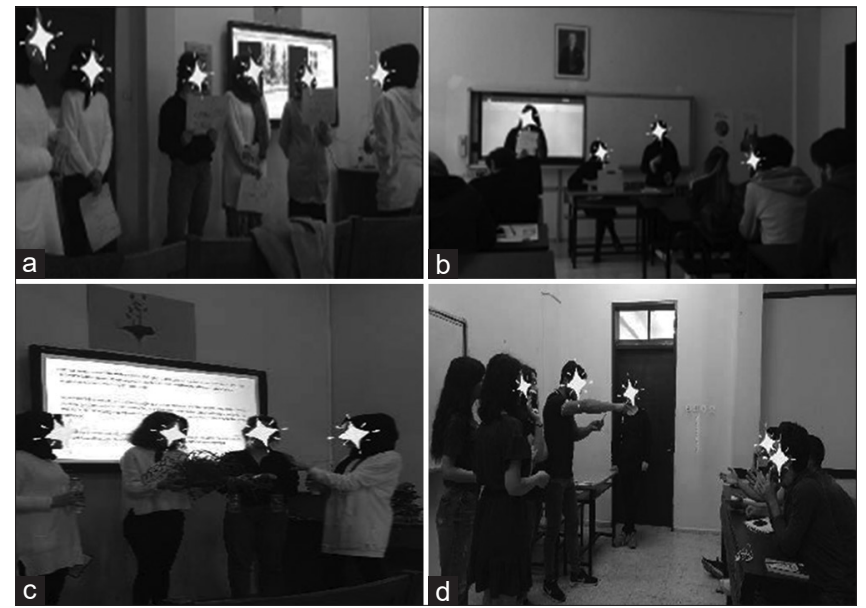

Figure 2 (a) The students carrying out a competition in the form of question-answer about soil pollution (Group 3). (b) The students were playing guitar and singing songs about global warming (Group 4). (c) The students were demonstrating an experiment on soil pollution that explained soil erosion and the importance of afforestation (Group 3). (d) The students were playing a Taboo game with the words they have prepared on air pollution (Group 2) activities. Students in each group created activities and worked together before their presentations. At this stage, we helped them to associate the activities in their work with the types of MI. During the group presentations, we ensured that students listened carefully and participated in the activities eagerly. MII and EIS were applied to students at the end of the procedure.

\section{Data Analysis}

To determine the relationship between the students' ecological intelligence and the types of MI, total scores were first calculated for the types of MI, and the sub-dimensions of EIS. Pearson's correlation coefficient was used to find the relationship and to test the significance at the $(\alpha=0.01$ and $\alpha=0.05$ ) level.

Later on, we analyzed the interviews in inductive and comparative ways (Merriam and Tisdell, 2015). Considering our research questions, we determined the codes and main themes. The themes were generated by review of literature and comments of the researchers. Any disagreement was resolved through arguments between the researchers. As a consequence of that, $98 \%$ inter-coder agreement was reached.

\section{RESULTS}

\section{Profiles of the Students}

The results of the average scores $(\bar{x})$ and levels the students got from MII are shown in Table 2. We found out that the students were highly developed in the types of LM, Visual/Spatial (VS), Bodily/Kinesthetic (BK), InterP and IntraP, and moderately developed in the types of VL, MR, and N.

\section{Connections between the Sub-Dimensions of EIS and the Types of MI}

To assess the correlations between the sub-dimension of EIS and the types of MI, both quantitative and qualitative findings were considered. The correlation between the points scored in the dimensions of the scale EIS and the points scored in MI was assessed in terms of quantitative findings (Table 3).

According to the correlation results, we found that the intelligence type which has the most correlation with the subdimensions of EIS was InterP. Table 3 indicates that InterP is statistically, significantly, and moderately correlated with ECPB $(r=0.46 ; p<0.05)$, ES $(r=0.41 ; p<0.05)$, and EKS $(\mathrm{r}=0.33, \mathrm{p}<0.05)$ (Ratner, 2009). Moreover, we determined moderate relations between $\mathrm{BK}$ and VS and the sub-dimensions of EIS.

\begin{tabular}{|c|c|c|c|c|c|c|c|c|}
\hline $\begin{array}{l}\text { Types of MI } \\
\text { Score }\end{array}$ & VL & LM & VS & BK & MR & InterP & IntraP & n \\
\hline$\overline{\mathrm{x}}$ & 23 & 28 & 26 & 26 & 22 & 26 & 26 & 23 \\
\hline Level & $\mathrm{MD}$ & HD & HD & HD & MD & HD & HD & MD \\
\hline
\end{tabular}

MD: Moderately developed; HD: Highly developed 


\section{Table 3: Pearson's correlation results}

\begin{tabular}{lcccccccc} 
Sub-dimensions of EIS & \multicolumn{9}{c}{ The types of MI } \\
\cline { 2 - 8 } & VL & LM & VS & BK & MR & InterP & IntraP & $\mathbf{n}$ \\
\hline ECPB & -0.02 & -0.06 & $0.38^{* *}$ & 0.03 & $0.13^{*}$ & $0.46^{* *}$ & $0.20^{* *}$ & $0.15^{* *}$ \\
HEIP & 0.00 & -0.10 & 0.07 & 0.09 & 0.06 & 0.09 & 0.08 & $0.23^{* *}$ \\
ES & 0.07 & 0.03 & $-0.12^{*}$ & $0.13^{*}$ & 0.04 & $0.41^{* *}$ & $0.13^{*}$ & 0.04 \\
EKS & $0.12^{*}$ & $-0.19^{* *}$ & -0.01 & $0.42^{* *}$ & 0.07 & $0.33^{* *}$ & 0.02 & 0.07 \\
\hline
\end{tabular}

$* \mathrm{p}<0.05, * * \mathrm{p}<0.01$

In addition to the correlation analysis, the student notes assessment conducted after completing the activities also presented the relation between the sub-dimensions of EIS that students considered dominant in the activities of the group presentations and the types of MI. The images used in Figure 3 are associated to the sub-dimensions of EIS.

The most dominant sub-dimension of the EIS was ECPB (Figure 3). This might be mostly due to the fact that the activities carried out mostly include overall perception of consumption, environmental factors created by this consumption, and production and marketing state of ecological products. ES was also a remarkable sub-dimension of EIS in these matchings. In this sense, we can infer that this subdimension emerged because the themes addressed during the activities have promoted environmental sensitivity such as preventing damage to the environment, reducing disposal of hazardous wastes, and preferring renewable energy resources.

\section{Students' Responses on the Effectiveness of the Types of MI about Their Ecological Awareness}

Frequency distribution of the students' responses to the questions investigating which types of MI they think are the most and least effective intelligences for their level of EI and sample quotes are shown in Figure $4 \mathrm{a}$ and $\mathrm{b}$.

In their comments on the activities, the students stated that those with improved in-class interaction were more effective on environmental awareness. They emphasized that the activities that let them build critical thinking and inquiry skills such as games, dramas, and interviews were particularly effective. They also expressed those activities with visual tools such as pictures, graphics, and videos were important and effective in drawing attention to the subject. The following quotes revealed that the students herein associated the environmental awareness and the types of MI in the activities they participated in varying aspects.

I believe employing bodily-kinesthetic intelligence through drama has been effective. We explained what actions are needed not to cause soil pollution. We informed about what products are recycled and how and in what forms of materials they are used after being recycled. We both had fun and learned at the same time. (S18)

InterP was more effective. The games such as Kahoot and Taboo created a more participatory setting. It was not boring. They inspired an interest for social and environmental issues among us. (S58)
These quotes clearly indicated that among the most dominant of the less effective intelligences on ecological awareness were VL intelligence and MR intelligence. In VL intelligence, the activities were mostly PowerPoint presentations/instructions/ poems. Such activities were mostly intended to transfer knowledge, and the overall impression concerning these activities was that they did not inspire for commenting or inquiring. The students noted that such activities diminished the interest for and appeal of the issue, as well as its comprehensibility.

For me, verbal-linguistic intelligence was less effective in my learning. Because we prepared and performed a presentation, staging facilitates long-lasting understanding of an issue. Ido not think we can have a continuous understanding unless we associate the things we read with our lives. (S7)

\section{Students' Responses on the Process of EE Course}

Addressing environmental issues within the scope of activities of $\mathrm{MI}$ in the classroom environment provided acquirements for the students in various aspects. The most interesting finding was that the activities of varying intelligences appealed to many students and helped them stay focused throughout the activities (Table 4).

It is clear in the quotes that the activities have been brought the students new experiences.

The class was conducted within the scope of the theory of MI, which taught us how to use multiple teaching methods for teaching about environmental issues. It was particularly engaging for me to employ dramatic activities. For example, I used to be able to teach about soil pollution, which was my subject, only through scientific methods, and now can teach it with sketch activities. (S28)

Employing activities of MI allowed us to participate in the class of EE more effectively, and we did a preliminary preparation for collecting information about the topics by ourselves. Then, in classroom, we all taught our subjects in accordance with the theory of MI. We have acquired a new and different experience. (S46)

Another noteworthy finding is that these activities were also useful in raising ecological awareness, which is the main goal herein. To give an example, one of the students is quoted to state that environmental issues can be taught in a more sensible and permanent way. 


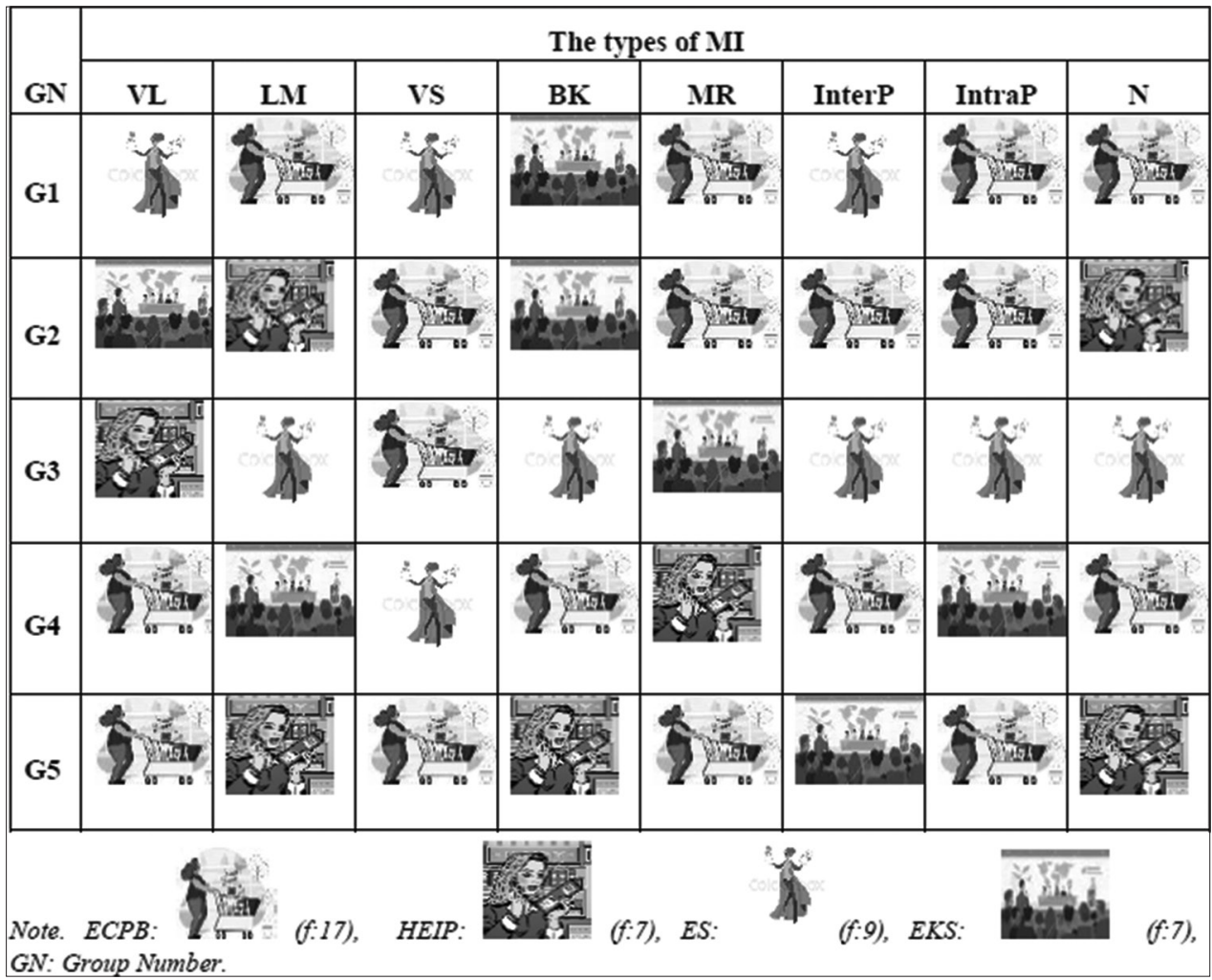

Figure 3: Matching representation of the group activities among the types of $\mathrm{MI}$ and the sub-dimensions of EIS

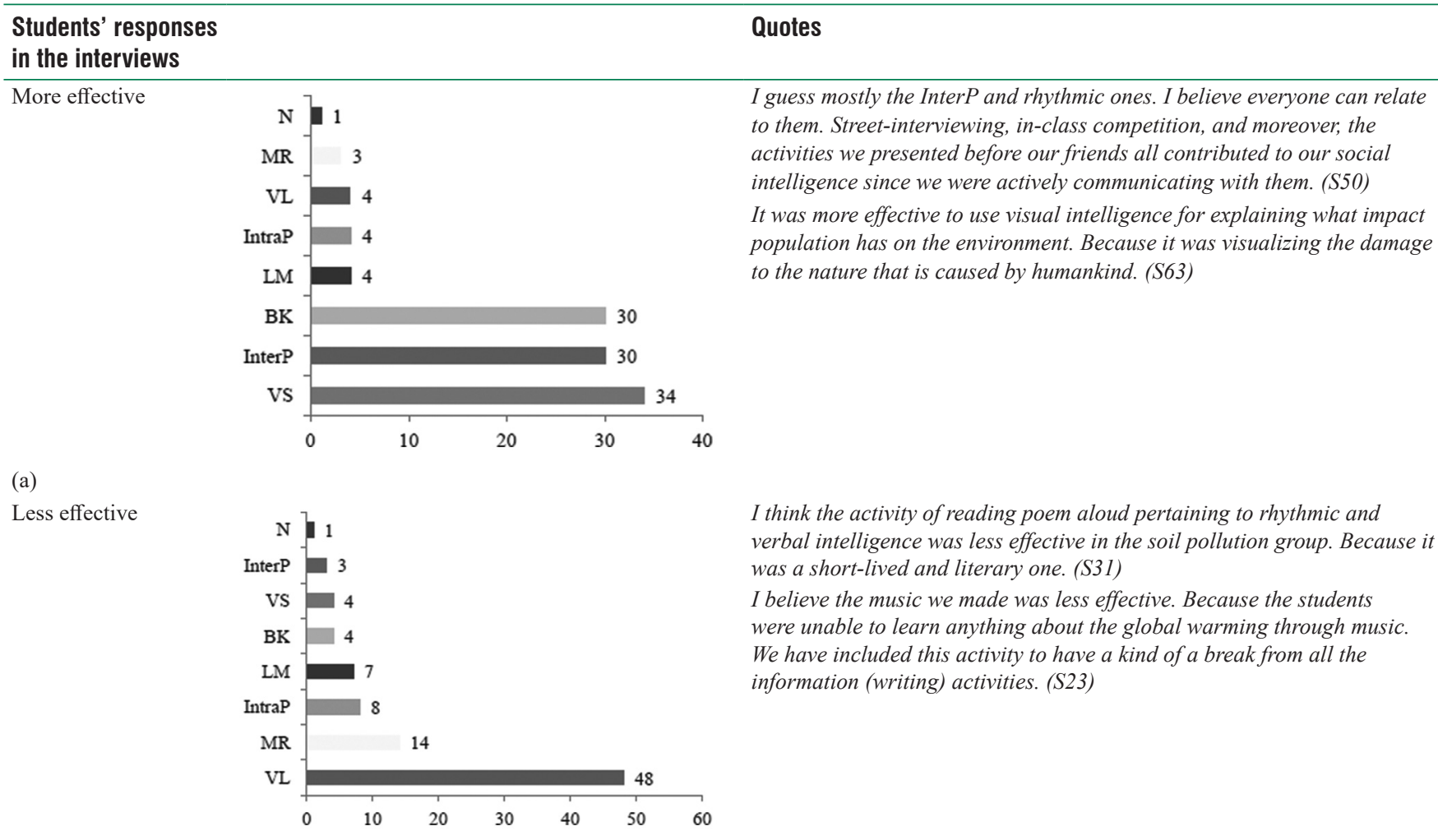

Figure 4: (a) Frequency distribution of the students' responses (b) Frequency distribution of the students' responses

I think it was different that the class was administered in accordance with the theory of MI. Everyone used different types of MI and did creative environmental activities. I have realized how much environmental pollution people are 


\begin{tabular}{lll}
\hline Table 4: The themes of the interview questions & & \\
\hline Themes & $\mathbf{f}$ & Lack of the students' activities in the process \\
\hline Benefits of the process & 33 & • Difficulties in designing activities \\
\hline - Improving motivation for course & 32 & • Inadequate communicative skills \\
- Active participation & 20 & • Inexperience \\
- Creating a multiple learning environment & 16 & • Inability of in-group communication \\
- Meaningful learning & 14 & • None \\
- Improving in-class interaction & 14 & \\
- Improving ecological awareness & 10 & 18 \\
- Ecological sensitivity &
\end{tabular}

causing. I have also realized once again that environmental pollution does do damage to all the living. (S47)

The drawback where the students felt the most inadequate is designing activities for each type of MI. We also found that students had difficulties in activities such as drama and role-playing for bodily-kinesthetic intelligence. Moreover, some students expressed about the difficulty of producing a musical piece of work while designing activities for rhythmical intelligence.

I have not done a presentation based on TMI in my education life before. I was anxious as it was the first time. The reason for my concern was the lack of knowledge about subject and fear of not being able to perform any activity. I was unable to conduct extensive research. (S20) I was not satisfactorily creative. I had difficulties in coming up with activities for each form of intelligence. It is not that easy to produce new things. (S38)

We had our drawbacks in drama. Because, we have not performed any drama-based instruction before. We were not effective enough in employing our actions. (S29)

All these difficulties might have emerged because they were dealing with ecological subject for the first time, preparing group activities, pushing their creativity, and needed to act collaboratively.

\section{DISCUSSION, CONCLUSIONS, AND IMPLICATIONS}

We examined the relation between the types of MI that are commonly applied in education and the sub-dimensions of ecological intelligence, which foregrounds a theme of being ecologically intelligent. We also stressed that ecological awareness can be attained through activities of MI. Theoretical knowledge runs short in the field of education to ensure that students act focusing on ecological problems to tackle these problems. Referring to this statement, in their study where Hungerford and Volk (2005) focused on the relation between environmental knowledge and behavioral changes, the researchers reported that having environmental knowledge does not necessarily result in long-term behavioral changes while developing personal connections, collective actions and a sense of responsibility for environmental issues is a critical factor in changing the behaviors. It is another critical fact that human actions need the interconnection between mind and body (Lehtonen et al., 2018). It is where activities of MI inevitably take on an efficient role. Therefore, the acquirement of ecological knowledge and exploration of ideas should take many forms music, movement, introspection, cooperation, and visually oriented experiences as well as language and math-oriented experiences. Students should therefore internalize ecological concepts both internally and experientially by applying them in a learning setting. Given the fact that humans are not naturally born environmentalists, it should be clear that ecologically intelligent abilities are to be acquired through multiple learning by education. Within this context, our study contributes as students both practiced during activities of MI and internalized ecological concepts during such activities.

There is a very limited number of studies in the literature that point out how activities based on the theory of MIs can improve ecological awareness (Baş, 2010; Herwina, 2018; Stevenson, 2007; Strife, 2010). To give an example, a study where Baş (2010) applied the MIs instructional strategy reported that this strategy enhanced students' environmental awareness knowledge levels. Studies also underline students need to be actively engaged in activities to acquire better ecological awareness (Aydede-Yalçın, 2016; Ballantyne and Packer, 2002; El Batri et al., 2019; Okayama, 2019). In a meta-analysis conducted by Arik and Yilmaz (2020), they found that EE through active learning yielded broadly productive outcomes. In our study as well, students expressed that they enjoyed and had better motivation and ability to learn comprehensibly when given the chance to put their work into action and to act collectively. Motivation is among the greatest factors that help students acquire ecological awareness and convert this awareness into behavioral actions (Aliman et al., 2019; Hidayat et al., 2017; Kollmuss and Agyeman, 2002). Jensen and Schnack (1997) mentioned on environmental action as an educational approach. This approach focuses on developing young people's critical thinking and the understanding, motivation, and skills to act on their values. Therefore, according to our results, these practices are useful both in terms of meaningful learning and promoting motivation for ecologically-conscious behaviors. 
Our results also reveal that InterP is the type of MI that is most correlated with ecological intelligence. This result is due to the fact that students prepared their environmentthemed presentations in an interactive manner and practice the activities that included various play techniques such as taboo, Kahoot, as well as interactive competitions, dramas, and interviews by means of in-class dialogues between the groups. We can therefore infer that in-class activities concerning environmental issues and ecological concepts can be effective if developed for the InterP type of intelligence. In parallel to this conclusion, Petruta (2013) used the technique of brainstorming to ask students to propose ideas for collecting and recycling wastes and found out that the technique activated students' ecological and social intelligences simultaneously. Vygotsky (1978) emphasized the importance of social interaction in education since social interaction could activate the mind and facilitate learning. Goleman (2006) reported that the human brain is wired to connect with others and the ability to do this successfully is a key ingredient in life's achievements. Students' cultural and environmental connections with each other might have outcomes caused by some of their behaviours and result in these outcomes having driving impact on others, thereby allowing them to improve their ecological intelligence (Bowers, 2010). Considering that intelligence is not solely a matter of mind but also a matter of action and place, ecological knowledge is also constructed jointly through interactions with others and within a setting (Yinger and Hendricks-Lee, 1993). Of all the results herein concerning how InterP is related to the sub-dimensions of ecological intelligence, it is a remarkable result that InterP is significantly and moderately correlated with ECPB, ES, and EKS. This result demonstrates that the students' presentations emphasized that environmental issues are mostly caused by overconsumption as the biggest human impact and focused on the consumption-related environmental factors and the measures that can be taken against them. Therefore, EKS during in-class activities allowed the students to ask questions about both their conscious purchasing behavior and their ES. So that, through EKS, students realized that humans stand as an essentially important factor for environmental issues, and they should be more sensitive about consumption. We can therefore conclude that ecological intelligence relies on not only the knowledge or cognitive components of environmental issues but also the perceptions and sensitivity of their impact. In this perspective, as a type of intelligence that reflects the cognitive and affective components mentioned herein, ecological intelligence should be developed within students in all its dimensions. What makes ecological intelligence improve as a whole is to make sure that the students participate in various activities of MI where they are actively and interactively engaged in a social setting.

The kind of social interaction that takes place along with active participation enhances ES through empathy, which also enables individuals to relate to others' feelings. In our study, students were able to address environmental issues from different perspectives and develop empathy during various dialogue-mediated activities such as developing creative drama, playing a music instrument, and singing songs, as well as playing games and doing experiments. Goleman et al., (2012) stressed that social intelligence and empathy support individuals to attain ecological intelligence, and that these components which activate cognitive and affective skills in dealing with ecological problems should be recognized as the integral parts of a whole. Similarly, Shumba (2011) and Sterling (2009) also stated that ecological intelligence is related to either cognitive area or affective area. Furthermore, Basu and Mermillod (2011) also noted that emotional mind and cognitive mind are needed to exhibit environmentally efficient behaviors. Al-Balhan (2006) developed the structured program that included activities of MI to enhance the prospective teachers' ecological intelligence and ecological sensitivities. He observed that the level of their ecological intelligence and consequently ES was improved through a structured program of Self-Instructional Modules in EE included fieldbases activities. Stating that among the goals of ecological intelligence is to improve social responsibility. Sterling (2009) maintained that social interaction is an important component in understanding environmental problems. The students' responses in their activities and opinions concerning their understanding of environmental problems are indicators of their ES. Based on the results in this regard, we can deduce that the types of intelligences referred are mutually interacting.

In our study, along with social intelligence, we found out that activities based on BK and VS intelligences were also effective in terms of ecological intelligence. Reporting that kinesthetic learning components are particularly effective in learning, studies also recommend that an education package that is based on kinesthetic learning and where visual images are used is developed for EE (Land, 2013). Students preferred especially such activities as drama and role play as activities of MI and expressed that they enjoyed performing or watching them. Österlind (2018) carried out a workshop using drama techniques such as bodily expressions, visualizations, and role-play on the subject of environmental problems. She affirmed that drama allows participants to work on real problems and contribute to more realistic learning experiences. Such activities can actually be effective in various types of intelligences including InterP, BK, VL, and VS intelligences and therefore support the dynamic interaction between the types of intelligence. We also observe that these intelligences which are in a dynamic relationship with each other allow ecological awareness, understanding and openness. The many recognized intelligences do help people to understand life what are, in fact, the interconnected, interactive aspects of the self: body, mind, emotion, and spirit (Gardner, 1983).

Our results also assert that ecological intelligence is connected with intrapersonal, musical and naturalist intelligences. It is utterly a delusion that nature-themed activities can improve only naturalist intelligences of students (Anderson, 2017). Such activities enable students to use various other types of intelligences like logistic and visual intelligences concerning 
organic/inorganic life in the nature, nature events, ecological balance, ecological lifestyle, and current ecological problems. Of specific importance to the theory of MIs is that the various intelligences often work together in concert rather than in isolation. Hence, a human being might employ several intelligences at a time to understand a particular problem or manage a situation (Sternberg, 1999). In their study, Sangsongfaa and Rawang (2016) applied the integrated model of EE and communicative English based on TMI toward environmental issues such as solid waste, air pollution, water pollution, soil pollution, chemical contamination in soil, chemical application in agriculture. The results of the study indicated that this model based on TMI has been useful in terms of appropriateness of content, activities, and benefit. Similar with our results, Jacobs (2013) asserted that an MI approach to education supports humans to reach our potentials as caring people, people who care for ourselves, for each other, for the planet, and for our fellow animals.

Students also stated that the least effective types of intelligences for ecological awareness have been VL and MR intelligences. It might be because they preferred direct instruction method in verbal intelligence. Among the reasons of distraction during the presentations could be the lack of presentation techniques that would encourage students to establish dialogue or to think about and inquire about a topic. In an educational process addressing sustainability and the green economy, Micangeli et al. (2014) reported that the groups of students who preferred verbal learning had poorer connections within their groups compared to others with different learning preferences. They stated that this stemmed from the preference of verbal intelligence (mainly reading) is quite uniform. In MR intelligence, students had a difficulty in encountering or creating lyrics/songs that properly addressed their topic. The results from the interviews also reveal it. It was particularly challenging for students to design activities of MR and BK intelligences. This challenge might have emerged because students were slightly informed about ecological subjects and under experienced and anxious about producing lyrics and songs or performing activities such as role-play and drama to address these subjects. Contrary to this situation, studies propound that EE assisted with music improves students' academic achievements, reduces behavioral issues, and enhances social interactions among other benefits, as supported by TMI (Nganji, 2013; Ramsey, 2002; Turner and Freedman, 2004). For this reason, when designed and practiced properly, activities of musical intelligence can be of great use in improving ecological intelligence.

Consequently, we can assert that activities of MI help students to develop physical, intellectual, social and emotional skills and besides they can acquire ecological awareness and sensitivity. Hence, MI can offer students the ability to contextualize learning through a holistic lens that includes environmentally responsible emotions, values, sensitivity for the environment, responsible environmental behavior and knowledge about nature and ecology, social action skills, and growth. Activities of MI can create a process that provide experiences that enable students to better internalize and understand the true characteristics and qualities of natural and human systems on earth.

\section{REFERENCES}

Akkuzu, N. (2016). Towards a profound ecological understanding: Statistical attempts to measure our ecological intelligence. International Journal of Social Sciences and Education, 6(2), 198-216.

Al-Balhan, E.M. (2006). Multiple intelligence styles in relation to improved academic performance in Kuwaiti middle school reading. Digest of Middle East Studies, 15(1), 18-34.

Aliman, M., Budijanto, S., \& Astina, I.K. (2019). Improving environmental awareness of high school students in Malang city through earthcomm learning in the geography class. International Journal of Instruction, 12(4), 79-94.

Anderson, B. (2017). Using Dr. Howard Gardner's Theory of Multiple Intelligences to Connect $4^{\text {th }}-8^{\text {th }}$ Grade Students to Nature. School of Education Student Capstone Projects, No. 89. Available from: https:// digitalcommons.hamline.edu/hse_cp/89

Arık, S., \& Y1lmaz, M. (2020). The effect of constructivist learning approach and active learning on environmental education: A meta-analysis study. International Electronic Journal of Environmental Education, 10(2), 44-84.

Aydede-Yalçın, M.N. (2016). The effect of active learning based science camp activities on primary school students' opinions towards scientific knowledge and scientific process skills. International Electronic Journal of Environmental Education, 6(2), 108-125.

Ballantyne, R., \& Packer, J. (2002). Nature-based excursions: School students' perceptions of learning in natural environments. International Research in Geographical and Environmental Education, 11(3), 218-236.

Baş, G. (2010). The effects of multiple intelligences instructional strategy on the environmental awareness knowledge and environmental attitude levels of elementary students in science course. International Electronic Journal of Environmental Education, 1(1), 53-80.

Basu, A., \& Mermillod, M. (2011). Emotional intelligence and socialemotional learning: An overview. Psychology Research, 1(3), 182-185.

Beck, U. (2009). World at Risk. Polity Press.

Bowers, C.A. (2010). Educational reforms that foster ecological intelligence. Teacher Education Quarterly, 37(4), 9-31.

Eilam, E., \& Trop, T. (2012). Environmental Attitudes and environmental behavior which is the horse and which is the cart? Sustainability, 4(9), 2210-2246.

El Batri, B., Alami, A., Zaki, M., Nafidi, Y., \& Chenfour, D. (2019). Promotion of the Environmental knowledge and behavior through the Moroccan syllabus of sciences in the middle school. International Electronic Journal of Elementary Education, 11(4), 371-381.

Gardner, H. (1983). Frames of Mind: The Theory of Multiple Intelligences. Basic Books.

Gerring, J. (2017). Case Study Research: Principles and Practices $2^{\text {nd }}$ ed. Cambridge: Cambridge University Press.

Goleman, D. (2006). Social Intelligence: The New Science of Social Relationships. Bantam Books.

Goleman, D. (2009). Ecological Intelligence: How Knowing the Hidden Impacts of What We Buy Can Change Everything. Broadway Books.

Goleman, D., Barlow, Z., \& Bennett, L. (2010). Forging new norms in new orleans: From emotional to ecological intelligence. Teacher Education Quarterly, 37(4), 87-98.

Goleman, D., Bennett, L., \& Barlow, Z. (2012). Ecoliterate: How Educators Are Cultivating Emotional, Social, and Ecological Intelligence. JosseyBass Publishers.

Gruenewald, D. (2003). Foundations of place: A multidisciplinary framework for place-conscious education. American Educational Research Journal, 40(3), 619-654.

Herwina, H. (2018). Garden based learning strategy instilling environmental consciousness in early childhood. Indonesian Journal of Early Childhood Education Studies, 7(1), 19-26.

Hidayat, A., Sarwono, M., \& Yusup, Y. (2017). Earthcomm-based 
multimedia learning of geography in improving learning motivation and spatial ability of the high school students. Advances in Social Science, Education and Humanities Research, 158, 1-10.

Hornbuckle, C.A. (2008). Ecological Intelligence: British Women Writers and the Environmental Tradition. Unpublished Doctoral Dissertation. University of South Carolina, USA.

Hungerford, H.R., \& Volk, T.L. (2005). Changing learner behavior through environmental education. In: Hungerford, H.R., Bluhm, W.J., Volk, T.L., \& Ramsey, J.M., (Eds.), Essential Readings in Environmental Education. Champaign: Stipes Published L.L.C NEST. pp. 313-328.

Jacobs, G. (2013). Teaching Meat Reduction: Insights from Multiple Intelligences Theory. Available from https://www.academia. edu/5134571/Teaching_Meat_Reduction_Insights_from_Multiple_ Intelligences Theory

Jensen, B.B., \& Schnack, K. (1997). The action competence approach in environmental education. Environmental Education Research, 3(2), 163-178.

Jeronen, E., Jeronen, J., \& Raustia, H. (2009). Environmental education in Finland a case study of environmental education in nature schools. International Journal of Environmental and Science Education, 4(1), $1-23$.

Kagawa, F., \& Selby, D. (2010). Education and Climate Change: Living and Learning in Interesting Times. Routledge.

Kainth, G.S. (2009). Environmental awareness among school teachers. ICFAI Journal of Environmental Economics, 7(1), 34-50.

Koger, S. (2013). Psychological and behavioral aspects of sustainability. Sustainability, 5(7), 3006-3008.

Kollmuss, A., \& Agyeman, J. (2002). Mind the gap: Why do people act environmentally and what are the barriers to pro-environmental behavior? Environmental Education Research, 8(3), 239-260.

Land, C. (2013). School project: Determining the predominant learning style from the VAK learning styles model in KS2 to enhance environmental education. The Plymouth Student Scientist, 6(1), 332-362.

Lehtonen, A., Salonen, A., Cantell, H., \& Riuttanen, L. (2018). A pedagogy of interconnectedness for encountering climate change as a wicked sustainability problem. Journal of Cleaner Production, 199, 860-867.

Leka, S., Jain, A., \& World Health Organization. (2010). Health Impact of Psychosocial Hazards at Work: An Overview. Geneva: World Health Organization. Available from: https://apps.who.int/iris/ handle/10665/44428

Maria, M.C. (2020). Effect of Ecological Intelligence on Developing Ecological Sensitivity among Prospective Teachers. Shashwat Publication.

Marinescu, P., \& Burcea, M. (2012). Information and ecological behaviour towards the natural resources consumption of the population of Bucharest. Amfiteatru Economic Journal, 14(31), 142-156.

McCallum, I. (2008). Ecological Intelligence: Rediscovering Ourselves in Nature. United States: Fulcrum Inc.

Merriam, S.B., \& Tisdell, E.J. (2015). Qualitative Research: A Guide to Design and Implementation. $4^{\text {th }}$ ed. Jossey-Bass Publishers.

Micangeli, A., Naso, V., Michelangeli, E., Matrisciano, A., Farioli, F., \& Belfiore, N.P. (2014). Attitudes toward sustainability and green economy issues related to some students learning their characteristics: A preliminary study. Sustainability, 6, 3484-3503.

Nganji, E.N. (2013). Effect of Song on Fifth Grade Students' Environmental Education Knowledge and Retention. Minnesota: University of Minnesota Digital Conservancy. Available from: https://hdl.handle. net $/ 11299 / 187549$

Okayama, S. (2019). Student-led environmental management system in Chiba university. International Journal of Sustainability in Higher Education, 20(8), 1358-1375.

Österlind, E. (2018). Drama in higher education for sustainability: Workbased learning through fiction? Higher Education, Skills and WorkBased Learning, 8(3), 337-352.

Petruta, G.P. (2013). Multiple intelligences stimulated within the lessons by the practicant students from the faculty of sciences. Procedia Social and Behavioral Sciences, 76, 676-680.

Piaget, J. (1969). The Child's Conception of the World. London: Kegan Paul, Trubner, and Co. Ltd.

Ramsey, D. (2002). The role of music in environmental education: Lessons from the cod fishery crisis and the dust bowl days. Canadian Journal of Environmental Education, 7(1), 183-198.

Ratner, B. (2009). The correlation coefficient: its values range between $+1 /-1$, or do they? Journal of Targeting, Measurement and Analysis for Marketing, 17(2), 139-142.

Saban, A. (2002). Çoklu Zekâ Teorisi ve Eğitim. [Multiple Intelligence Theory and Education]. Nobel Yayin.

Sangsongfaa, C., \& Rawanga, W. (2016). The integration of environmental education and communicative english based on multiple intelligence theory for students in extended schools. International Journal of Environmental and Science Education, 11(12), 5776-5788.

Sethusha, M. J. (2006). How Primary School Learners Conceptualize the Environment and Environmental Education. Pretoria: University of Pretoria the Faculty of Education. Available from: https://repository. up.ac.za/bitstream/handle/2263/28350/dissertation.pdf;jsessionid $=93 \mathrm{~F} 50 \mathrm{C} 10 \mathrm{EDE} 2 \mathrm{EE} 487 \mathrm{~B} 1 \mathrm{~B} 77 \mathrm{~F} 1 \mathrm{D} 8 \mathrm{~B} 88 \mathrm{C} 69$ ? sequence $=1$

Shumba, O. (2011). Commons thinking, ecological intelligence and the ethical and moral framework of Ubuntu: An imperative for sustainable development. Journal of Media and Communication Studies, 3(3), 84-96.

Staples, A.F., Larson, L.R., Worsley, T., Green, G.T., \& Carroll, J.P. (2019). Effects of an art-based environmental education camp program on the environmental attitudes and awareness of diverse youth. The Journal of Environmental Education, 50(3), 208-222.

Steffen, W. (2013). A Report on the Angry Summer. Available from: https:// climatecommission.files.wordpress.com/2013/09/130408-angrysummer-report.pdf

Steffen, W., Crutzen, P.J., \& McNeill, J.R. (2007). The anthropocene: Are humans now overwhelming the great forces of nature? Ambio, 36(8), 614-621.

Sterling, S. (2009). Ecological intelligence: Viewing the world relationally. In: Stibbe, A., (Ed.), The Handbook of Sustainability Literacy: Skills for a Changing World, pp. 76-83, Green Books.

Sternberg, R.J. (1999). Successful intelligence: Finding a balance. Trends in Cognitive Sciences, 3(11), 436-442.

Stevenson, R.B. (2007). Schooling and environmental education: Contradictions in purpose and practice. Environmental Education Research, 13(2), 139-153.

Strife, S. (2010). Reflecting on environmental education: Where is our place in the green movement? The Journal of Environmental Education, 41(3), 179-191.

Taber, K.S. (2014). Ethical considerations of chemistry education research involving "human subjects". Chemistry Education Research and Practice, 15(2), 109-113.

Turner, K., \& Freedman, B. (2004). Music and environmental studies. Journal of Environmental Education, 36(1), 45-52.

Vaughan, C., Gack, J., Solorazano, H., \& Ray, R. (2003). The effect of environmental education on schoolchildren, their parents, and community members: A study of intergenerational and intercommunity learning. Journal of Environmental Education, 34(3), 12-21.

Vygotsky, L.S. (1978). Mind in Society: The Development of Higher Psychological Processes. Harvard University Press.

Wang, J., Zhu, M., Tang, X., He, M., XuGao, S.Y., \& Gu, J. (2010). Opportunities and challenges for environmental education at Yunnan's institutions of higher learning. Chinese Education and Society, 43(2), 82-93.

Wiek, A., Withycombe, L., \& Redman, C.L. (2011). Key competencies in sustainability: A reference framework for academic program development. Sustainability Science, 6, 203-218.

Wolff, L.A. (2011). Nature and Sustainability: An Educational Study with Rousseau and Foucault. Unpublished Doctoral Dissertation, Åbo Akademi University, Turku, Finland.

Yin, R.K. (2017). Case Study Research and Applications: Design and Methods. $6^{\text {th }}$ ed. SAGE.

Yinger, R., \& Hendricks-Lee, M. (1993). Working knowledge in teaching. In: Day, C., Calderhead, J., \& Denicolo, P., (Eds.), Research on Teacher Thinking: Understanding Professional Development, pp. 100-123, Falmer Press.

Zoldosova, K., \& Prokop, P. (2006). Education in the field influences children's ideas and interest toward science. Journal of Science Education and Technology, 15(3-4), 304-313. 